\title{
De novo in vitro shoot morphogenesis from shoot tip-induced callus cultures of Gymnema sylvestre (Retz.) R.Br. ex Sm
}

\author{
Tasiu Isah* ${ }^{*}$
}

\begin{abstract}
Background: Gymnema sylvestre is a medicinal woody perennial vine known for its sweetening properties and antidiabetic therapeutic uses in the modern and traditional medicines. Its over-exploitation for the therapeutic uses and to meet the demand of pharmaceutical industry in raw materials supply for the production of anti-diabetic drugs has led to considerable decline in its natural population.

Results: An efficient system of shoot bud sprouting from nodal segment explants and indirect plant regeneration from apical meristem-induced callus cultures of G. sylvestre have been developed on Murashige and Skoog (MS) medium amended with concentrations of cytokinins. Of the three growth regulators tested, $N^{6}$-benzylaminopurine (BAP) was the most efficient and $2.0 \mathrm{mg} \mathrm{L}^{-1}$ gave the best shoot formation efficiency. This was followed by thidiazuron (TDZ) and kinetin (Kin) but, most of the TDZ-induced micro shoots showed stunted growth. Multiple shoot formation was observed on medium amended with BAP or TDZ at higher concentrations. The produced micro shoots were rooted on half strength MS medium amended with auxins and rooted plantlets acclimatized with $87 \%$ survival of the regenerates.
\end{abstract}

Conclusions: The developed regeneration system can be exploited for genetic transformation studies, particularly when aimed at producing its high yielding cell lines for the anti-diabetic phytochemicals. It also offers opportunities for exploring the expression of totipotency in the anti-diabetic perennial vine.

Keywords: Plant tissue culture, Plant regeneration, Plant growth regulators, Phytochemicals, Gymnema sylvestre, Gymnemic acid, Micro shoots, Plantlets, Shoot morphogenesis

\section{Background}

Phytomedicine is the greatest source for the remedy of diseases nowadays and over $80 \%$ of human population relies on it for health care delivery due to the minimal side effects and low cost [1-4]. The increase in number of diabetic patients around the globe has led to exploitation of natural plant sources for its remedy among which Gymnema sylvestre is highly exploited for the therapeutic use. The woody climber belongs to the family Asclepiadaceae and is recognized in the traditional systems of medicine for the remedy of diabetes mellitus and several

*Correspondence: taasmore@yahoo.co.uk

Department of Botany, School of Chemical and Life Sciences, Hamdard University, New Delhi 110 062, India other therapeutic uses [1]. Its leaves produce glycosides, anthraquinones and gymnemic acid, which are ascribed the antidiabetic, sweetening and anti-inflammatory properties $[1,5]$. Overexploitation of G. sylvestre natural population coupled with poor seed germination capacity and low rooting ability during vegetative propagation are impediments to its rapid clonal multiplication to meet phytochemical demand of the pharmaceutical industry in raw materials supply for the production of anti-diabetic drugs and other medicinal uses [6].

In vitro clonal propagation offers rapid and efficient strategy for the production of disease-free clones en masse and for the conservation of natural population $[7,8]$. It also offer opportunities for the large-scale production and isolation of bioactive molecules produced 
by G. sylvestre that are used in the industrial production of its anti-diabetic drugs. However, initiating the in vitro cultures is constrained by difficulties in appropriate explant availability in a season and obtaining the most suitable one for the in vitro clonal production. De novo shoot morphogenesis forms the basis for which new genetic variations and biotechnological approaches can be applied to improve clonal multiplication of medicinal plants en masse, particularly when mature tissues can be used [7-11]. Further, indirect regeneration can be used to study details of dedifferentiation events through the developmental stages, with application in genetic transformation studies and selection of superior clones [7, 12, 13]. Developing the in vitro clonal propagation strategy has application in the large-scale production of G. sylvestre for its clones of therapeutic uses such as in the treatment of diabetes, the sweetening properties, and other pharmaceutical uses. Factors that influence in vitro clonal propagation efficiency of the G. sylvestre includes seedling age, explant, basal medium, plant growth regulators (PGRs) types and concentrations, organic supplements, antioxidants added into the culture medium and physiological state of explants [6].

Previous in vitro clonal propagation of G. sylvestre were achieved from mature explants through direct regeneration pathways $[6,14-16]$ and somatic embryogenesis (SE) from seedling explants [17] but, totipotency expression potential of its cells via de novo organogenesis from meristematic tissues-derived callus cultures have not been studied. The de novo shoot morphogenic pathway is not attainable with many woody plants due to the influence of genotype and specific requirement for certain cells having unique properties needed for initiation of meristematic primordial essential for the in vitro morphogenesis $[18,19]$. In the present study, axillary bud sprouting of nodal segment explants and plant regeneration from shoot tip-induced callus cultures were achieved in G. sylvestre, indicating totipotency expression potentials of the callus cultures.

\section{Results}

Cultured ex vitro collected and surface sterilized G. sylvestre nodal segment explants produced shoot buds within 3-4 weeks culture on solid MS medium added with most of the cytokinin types and concentrations tested (Fig. 1a). The response was earlier and more in cultures this growth regulators were amended at higher levels (above $1.0 \mathrm{mg} \mathrm{L}^{-1}$ ). For the organogenesis, shoot bud apical meristem of the induced micro shoots were used to initiate callus cultures (Fig. 1a, b). When upper most apical meristem of young buds (about 1-3 mm) were excised and cultured on solid MS medium added with 2,4-dichloropenoxy acetic acid (2,4-D) $\left(2.0 \mathrm{mg} \mathrm{L}^{-1}\right)$, profuse callus formation was observed within 2-3 weeks culture (Fig. 1b). The induced callus was yellowish-brown and faster in biomass production. Subsequent subculture of the callus onto fresh solid medium added with the same PGR concentration resulted in its slow growth accompanied with darkening of the yellowish-brown calli and increased compactness. Calli were then cultured on medium added with selected cytokinin types and concentrations for the organogenesis study. The response of the callus cultures to shoot morphogenesis was dependent on PGRs type and concentration amended into the cultivation medium (Table 1). After 4-5 weeks culture, formation of shoot buds were observed in most of the cultures, and was at higher frequency on media added with PGRs at $1-4 \mathrm{mg} \mathrm{L}^{-1}$ while $0.5 \mathrm{mg} \mathrm{L}^{-1}$ showed less efficiency (Fig. 1c-f). Histological studies showed densely packed meristematic cells in the upper-most region of the induced micro shoot apices and larger parenchymatous cells in the lower (Fig. 2f).

In this study, maximum shoot formation was observed with $N^{6}$-benzylaminopurine (BAP) added media followed by thidiazuron (TDZ) and least with the kinetin (Kin) (Table 1). Of the five concentrations tested, BAP at $2.0 \mathrm{mg} \mathrm{L}^{-1}$ was the most efficient; it produced an average of $7.92 \pm 0.81$ micro shoots with an average length of $2.38 \pm 0.43 \mathrm{~cm}$ per approximately $0.5 \mathrm{~g}$ callus at $79 \%$ efficiency while Kin at $0.5 \mathrm{mg} \mathrm{L}^{-1}$ was the least effective (Table 1). The micro shoots cultivated through three subcultures were separately excised for rooting using half strength MS medium added with indole 3-acetic acid (IAA), indole 3-butyric acid (IBA) or naphthalene acetic acid (NAA) concentrations $\left(0.5-3 \mathrm{mg} \mathrm{L}^{-1}\right)$. In most of the cultured micro shoots, root formation occurred within 3 weeks culture, and the observed rooting response evaluated and presented in Fig. 3, with a good sample in Fig. 2d. Higher concentration of IBA (above $1.0 \mathrm{mg} \mathrm{L}^{-1}$ ) produced large but longer, thick and abnormal-looking roots (Fig. 2c) while NAA and IAA at high and low levels were inefficient for rooting the micro shoots (Fig. 2a, b). However, best formation of the roots was achieved with the IBA-added media in comparison to the other auxins tested (Fig. 3).

\section{Discussions \\ Shoot formation}

The establishment of in vitro cultures for the clonal multiplication of medicinal plants offers an alternative strategy for the conservation and production of phytochemicals they produce. Factors that influence the in vitro morphogenesis includes explant type and its physiological ontogenetic age, the season of collection and size, among others $[7,20]$. In the case of G. sylvestre and many species, the in vitro morphogenesis could 


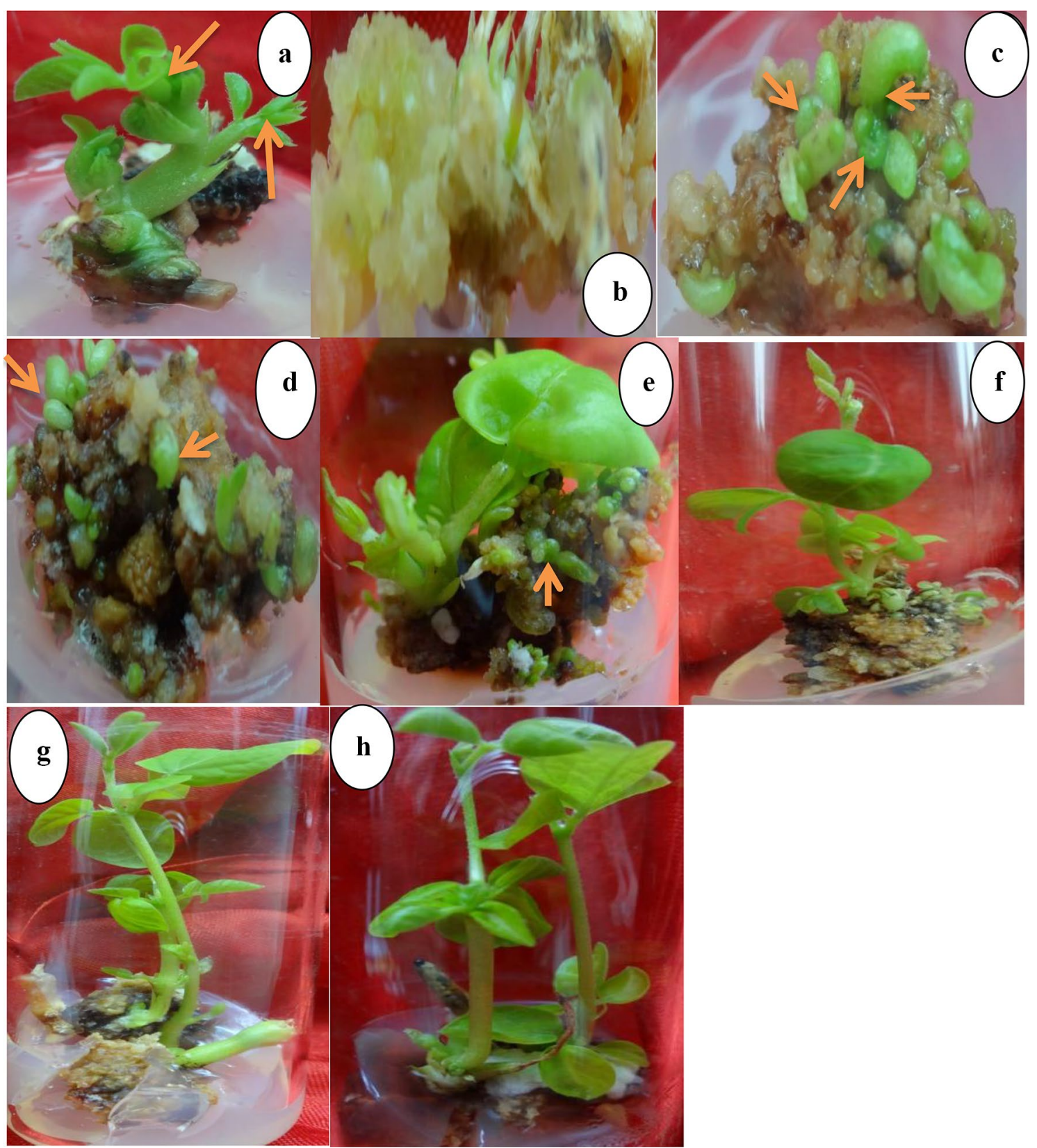

Fig. 1 a Micro shoot bud produced on MS medium added with BAP $\left(1.0 \mathrm{mg} \mathrm{L}^{-1}\right)$ using ex vitro obtained nodal segment explant from which shoot-tip was excised for callus induction, $\mathbf{b}$ callus induced from the excised shoot-tip explants, $\mathbf{c}-\mathbf{f}$ de novo shoot morphogenesis from the apical meristem-induced callus on MS medium amended with TDZ $\left(1.0 \mathrm{mg} \mathrm{L}^{-1}\right)$ after 5 weeks culture, $\mathbf{g}, \mathbf{h}$ elongation of the induced micro shoots on medium added with BAP $\left(1.0 \mathrm{mg} \mathrm{L}^{-1}\right)$ after 8 weeks culture

only be achieved when explants used to initiate the in vitro cultures are at a certain stage of development $[6,17,19]$. In previous studies, the indirect plant regeneration system of G. sylvestre were attempted using mature explant tissues of leaf, hypocotyl, cotyledons and nodal segment explants [17, 21, 22]. This prompted the experiment reported herein using ex vitro nodal segment of mature plants as an initial explant used to initiate micro shoot and from which the plant regeneration system was developed using micro shoot apical meristem. The juvenility of shoot-tip explant and its usual high IAA levels made it an ideal system for initiating callus cultures and subsequent organogenesis studies, and a possible explanation to the profuse callus 


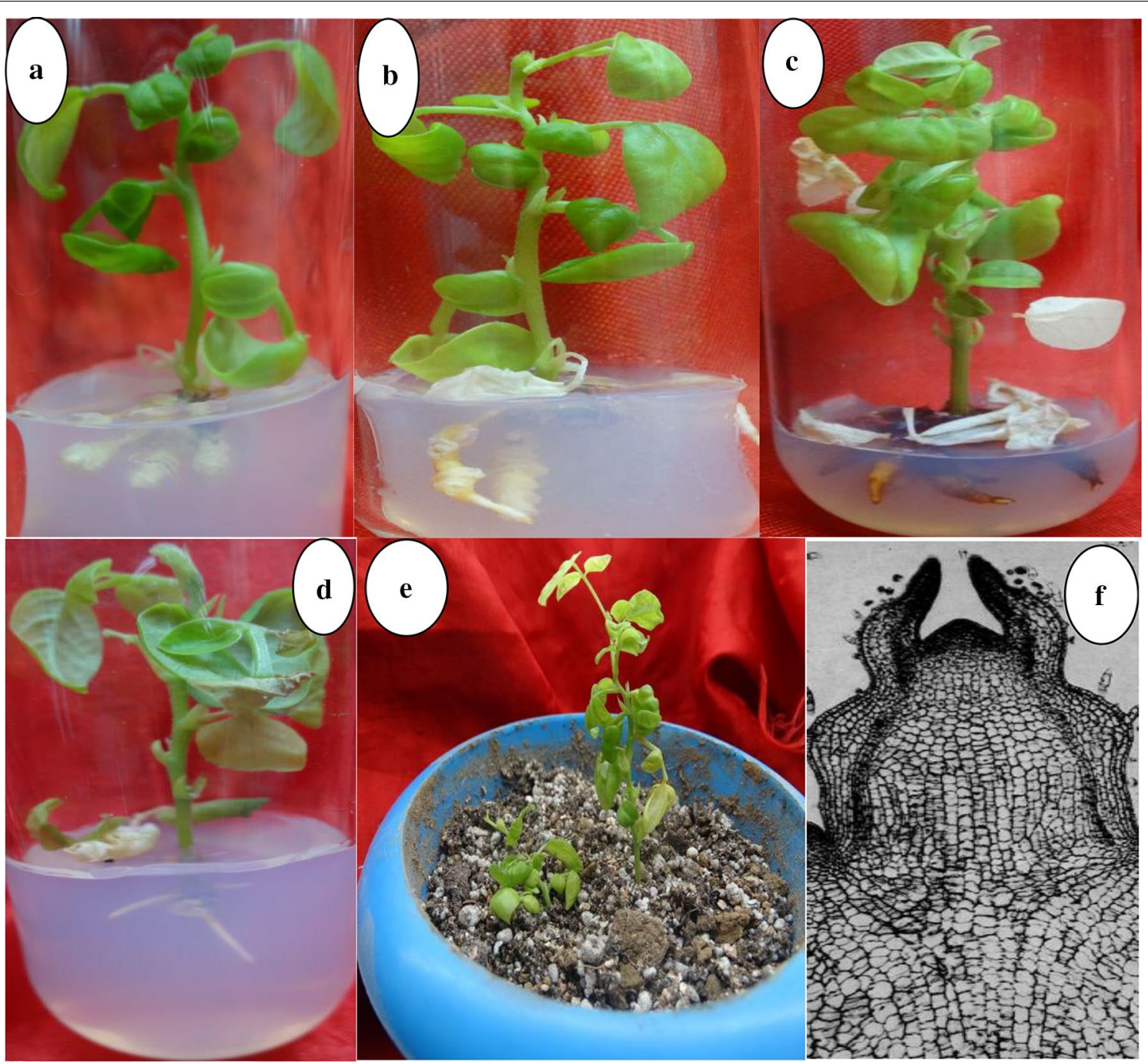

Fig. 2 a-d Rhizogenesis of the obtained micro shoots on solid media added with auxins; a IAA (1.0 mg L $\left.\mathrm{L}^{-1}\right)$, b NAA $\left(2.0 \mathrm{mg} \mathrm{L}^{-1}\right)$, $\mathbf{c | B A}\left(2.0 \mathrm{mg} \mathrm{L}{ }^{-1}\right)$, d IBA $\left(1.0 \mathrm{mg} \mathrm{L}^{-1}\right)$ after 3 weeks culture. e Acclimatization of the regenerated plants in a potted mixture of soilrite:perlite (1:1) after 2-months, $\mathbf{f}$ histological study of the micro shoots

induction observed in this study. Further, the advantages of developing indirect plant regeneration system of G. sylvestre using the apical meristem could have application in the production of disease-free plants which had been achieved with many woody and medicinal plants such as strawberry [23], Jatropha curcas [24] and recently with the Chilean strawberry [25]. For the organogenesis, calli were cultured on MS medium added with cytokinins at different concentrations due differential role they play in promoting cell division, the other aspects of in vitro morphogenesis that includes plant growth physiology and development by regulating gene expression, such as the expression of knotted 1 (kn1) homeobox family (exclusively expressed in apical meristem) essential for the in vitro morphogenesis [26]. The shoot-tip induced callus cultured on MS medium augmented with the cytokinins produced shoot buds at varied degree (by concentration of the cytokinins amended) within 2 weeks culture while for the control callus cultivation, proliferation without shoot bud initiation were observed (Fig. 1b-e). With the increased culture duration, the number, length and percentage micro shoot formation per culture tube showed variations associated with the cytokinins amended in the culture medium. Of the three cytokinins tested, BAP was the most efficient, followed by TDZ and Kin. However, higher concentrations of the cytokinins proved inhibitory to morphogenesis parameters (Table 1), 
Table 1 Effect of cytokinins on indirect shoot morphogenesis from apical meristem-induced callus cultures of Gymnema sylvestre cultivated for 6 weeks on solid Murashige and Skoog medium

\begin{tabular}{|c|c|c|c|c|c|}
\hline \multicolumn{6}{|c|}{ Concentration of the cytokinins $\left(\mathrm{mg} \mathrm{L}^{-1}\right.$ ) } \\
\hline BAP & TDZ & Kin & $\begin{array}{l}\text { Number of shoots per } \sim 0.5 \mathrm{~g} \\
\text { calli mass }\end{array}$ & Shoot buds initiated (\%) & $\begin{array}{l}\text { Length of the micro } \\
\text { shoots in } \mathrm{cm} \\
\text { (mean } \pm S E)\end{array}$ \\
\hline 0.5 & - & - & $3.94 \pm 0.42 d$ & $41.16 \pm 3.11 \mathrm{c}$ & $1.34 \pm 0.62 d$ \\
\hline 1.0 & - & - & $6.87 \pm 0.97 a$ & $63.42 \pm 2.81 a$ & $2.17 \pm 0.55 b$ \\
\hline 2.0 & - & - & $7.92 \pm 0.81 a$ & $79.42 \pm 2.73 a$ & $2.38 \pm 0.43 a$ \\
\hline 3.0 & - & - & $5.39 \pm 0.77 b$ & $58.4 \pm 3.17 \mathrm{~b}$ & $2.24 \pm 0.39 a$ \\
\hline \multirow[t]{11}{*}{4.0} & - & - & $4.03 \pm 0.91 c$ & $49.81 \pm 2.16 c$ & $2.14 \pm 0.32 b$ \\
\hline & 0.5 & - & $2.87 \pm 0.34 \mathrm{e}$ & $38.93 \pm 2.18 d$ & $1.18 \pm 0.48 c$ \\
\hline & 1.0 & - & $5.43 \pm 0.42 b$ & $58.37 \pm 1.62 b$ & $2.01 \pm 0.32 b$ \\
\hline & 2.0 & - & $6.78 \pm 0.67 a$ & $63.41 \pm 2.44 a$ & $2.14 \pm 0.41 b$ \\
\hline & 3.0 & - & $4.93 \pm 0.51 c$ & $51.22 \pm 3.81 b$ & $2.02 \pm 0.36 b$ \\
\hline & 4.0 & - & $3.67 \pm 0.47 d$ & $42.81 \pm 2.94 c$ & $1.99 \pm 0.29 c$ \\
\hline & & 0.5 & $2.14 \pm 0.25 \mathrm{e}$ & $31.42 \pm 1.15 d$ & $1.02 \pm 0.22 \mathrm{e}$ \\
\hline & & 1.0 & $4.21 \pm 0.33 c$ & $47.34 \pm 1.26 c$ & $1.86 \pm 0.34 c$ \\
\hline & & 2.0 & $5.17 \pm 0.18 b$ & $54.49 \pm 2.21 b$ & $2.02 \pm 0.29 b$ \\
\hline & & 3.0 & $3.21 \pm 0.26 d$ & $39.27 \pm 2.45 d$ & $1.78 \pm 0.41 c$ \\
\hline & & 4.0 & $2.11 \pm 0.34 \mathrm{e}$ & $31.38 \pm 1.87 d$ & $1.56 \pm 0.28 d$ \\
\hline
\end{tabular}

Obtained experimental data were inverse transformed prior to the statistical analysis. Mean values within column that are followed by the same letter are not significantly different at $p<0.05$ levels

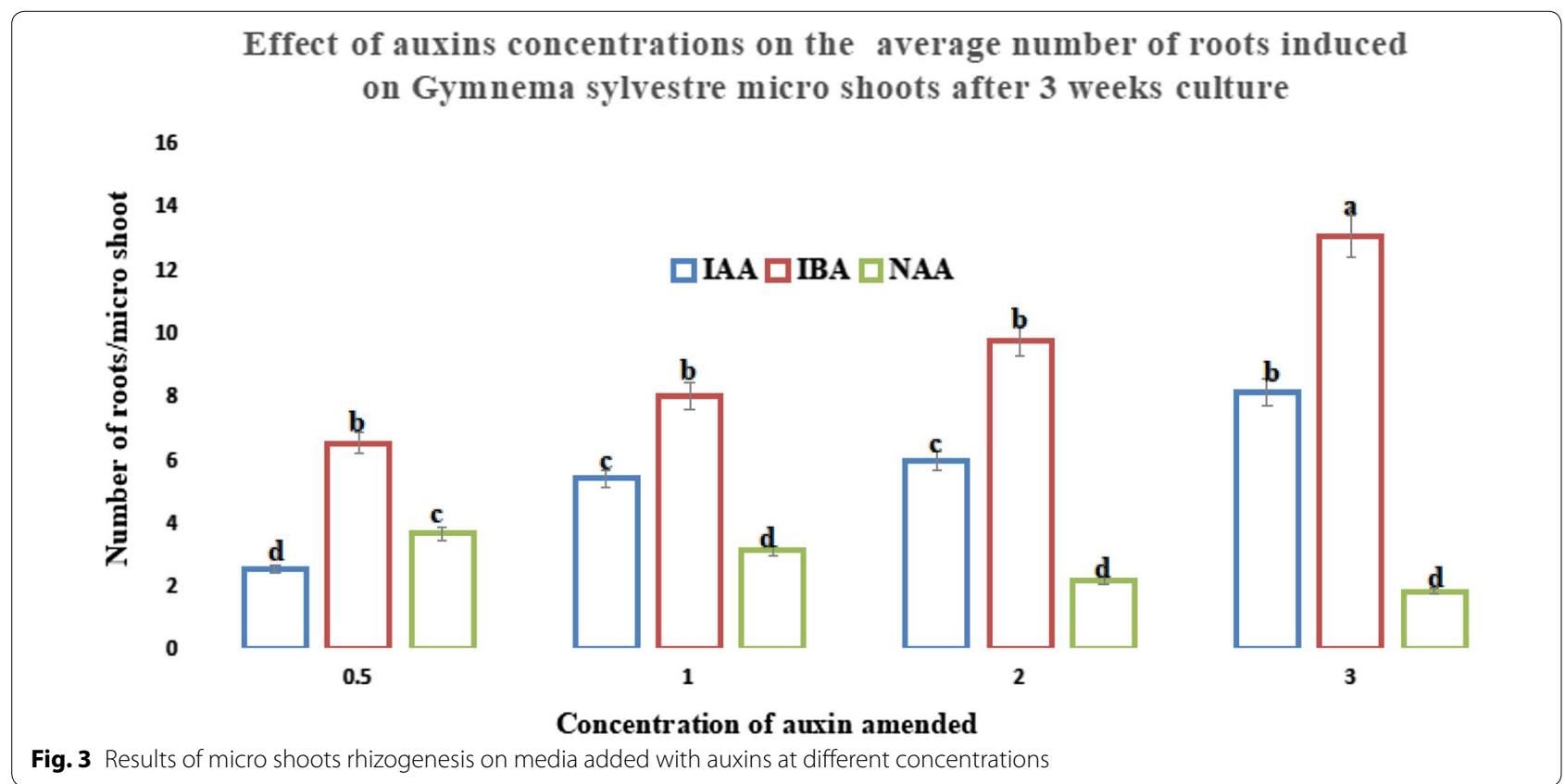

which explains differential cellular effect of the cytokinins amended in the culture medium. The cytokinins are essential compositions of plant tissue culture media that influence in vitro morphogenesis by their types and concentration(s) amended in the cultivation medium, and show variant effects on shoot growth parameters due to differential influence on growth and physiology through accumulation as endogenous cytokinins determined by rate of cellular metabolism. Previous studies on the organogenesis capacity of G. sylvestre on medium supplemented with BAP encountered formation of green, compact and hard granular callus when 
leaf and nodal segments were used as initial explants [21]. Kin produced light green, less hard and compact callus with greater biomass production. Combination of BAP with auxins produced more callus biomass over that with the Kin. Culture of this calli in liquid medium further enhanced the responses without shoot morphogenesis. Khatak et al. [22] obtained green callus cultures from leaf explants of G. sylvestre and pigmentation of the callus increased with increase in the concentration of cytokinins amended in the cultivation medium and subculture cycles, without morphogenesis. However, Ashok Kumar et al. [17] have earlier obtained embryogenic callus and subsequent SE when hypocotyl, leaf and cotyledons of $G$. sylvestre seedlings were used as initial explants for establishment of its in vitro cultures. In the meristem culture and subsequent micropropagation of Chilean strawberry accessions, the use of BAP in the cultivation medium increased plantlets multiplication up to 3-6 micro shoots/explant [25] while it gave more number of shoots over Kin when amended in the culture medium of Senna occidentalis hypocotyl-derived callus cultures [12]. In a recent reported experience with the in vitro cultures of Chonemorpha fragrance, TDZ showed more efficiency over BAP and Kin in the induction and proliferation of micro shoots [27]. In this experiment, compared to the other cytokinins tested, most of the TDZ-induced micro shoots showed stunted growth and were relatively shorter when compared to those produced by BAP-amended medium cultures. However, their subsequent culture on BAP, Kin-added or PGRs-free media promoted elongation, suggesting the inhibitory effect of TDZ on micro shoots elongation (Fig. 1g, h). Further, subculture of the micro shoots at 3-4 weeks interval per round to the fresh solid medium as the induction medium promoted high frequency multiple shoot formation by third subculture cycle. Formation of the multiple shoots was more on solid medium cultivation of the cultures added with higher levels of BAP or TDZ. Multiple shoot formation in the in vitro cultures of G. sylvestre had earlier been reported $[6,16]$ as well as with medicinal plants such as Mucuna pruriens [28] and Isolon wightii [29]. In the present experiment, multiple shoot formation was not observed on medium supplemented with Kin at higher and lower concentrations. In the shoot tipinduced callus cultures of Capsicum chinense Jacq. cv. Naga King Chili [30] and inverted hypocotyl explantinduced callus cultures of Solanum melongena L. cv. Arka, callus proliferation and pigmentation was accompanied by the induction of micro shoot primordial with TDZ as the most effective PGR among the others tested $[30,31]$. In most of the cultures used in the experiment reported herein, medium browning due to the leaching effect of phenolic compounds by callus and the produced micro shoots were observed. To minimize the effect, addition of ascorbic acid at $0.5 \mathrm{mg} \mathrm{L}^{-1}$ was attempted with success.

\section{Root formation}

Rhizogenesis is an essential stage but difficult task with most woody plants due to their differential response to root initiation in the in vitro cultures as well as during conventional methods of clonal propagation. For many of their in vitro cultures, addition of media supplements have become a requirement for stimulating rhizogenesis, due to the differential response they show to auxins metabolism which is influenced by the in vitro culture physiology. This is in turn determined by the medium composition for which the shoots were initiated in addition to genetic factors. In the present experiment, root induction from micro shoots was observed after 2 weeks cultivation in most of the cultures auxins were amended in the culture medium. Better formation of thin and healthy roots was achieved on half strength MS medium added with IBA at $1.0 \mathrm{mg} \mathrm{L}^{-1}$ (Fig. 2d). The induced roots elongated with lateral root formation from the primary roots, with increase in the culture duration using most IBA-amended medium cultures. In the case of NAA and IAA, abnormal root formation was observed in many cultures they were amended above $1.0 \mathrm{mg} \mathrm{L}^{-1}$ (Figs. 1, 2). Control cultures and those cultivated on media added with higher levels of NAA showed basal callusing of the micro shoots. Compared to the other auxins tested for the rhizogenesis of Capsicum chinense Jacq. cv. and Solanum melongena cv. Arka Shirish micro shoots, IBA was found more efficient over other auxins tested $[30,31]$ while higher levels of NAA resulted in abnormal and thick root formation in S. occidentalis [12]. In the present experiment, the in vitro regenerated plants were acclimatized in potted mixture of soilrite:perlite (1:2) and covered with polyethylene bags to retain high relative humidity in a controlled environment for 2 weeks. Later, the polyethylene bags were removed (Fig. 2e) for acclimatization of plantlets in green house before their transfer into the field condition for which $87 \%$ survival of regenerated plants were recorded after 2 months.

\section{Conclusions}

In conclusion, an efficient indirect plant regeneration system from callus cultures induced from micro shoot apical meristem that were in turn derived from ex vitro nodal segment explants of G. sylvestre have been developed. The system can be exploited for genetic transformation studies, particularly when aimed at producing its anti-diabetic phytochemicals through production of high yielding cell lines. It also offers opportunities for 
exploring the expression of totipotency in the callus cultures of the anti-diabetic medicinal woody vine.

\section{Methods}

Explant collection, preparation and cultures establishment Healthy nodal segment explants (from actively growing twigs) of about $1.0-2.0 \mathrm{~cm}$ length were collected from about 5-years-old G. sylvestre (during early morning hours) grown in the herbal garden of Botany department, Hamdard University New Delhi, India $\left(28^{\circ} 33^{\prime}\right.$ $41.9652^{\prime \prime} \mathrm{N}$ and $77^{\circ} 16^{\prime} 52.5288^{\prime \prime} \mathrm{E}$ ) during the months of October and November, 2013. The explants were washed thoroughly (using a pinch of cetrimide dissolved in tap water) for 1-3 min before subjected to the jet of running tap water for 10-20 min. Surface sterilization of the explants was performed in laminar air hood chamber using 70\% ethanol treatment for 2-5 min followed by $2-3$ rinses with sterile Milli-Q water. Further surface sterilization was done using freshly prepared $0.1 \%$ mercuric chloride solution for 2-3 min followed by rinses with sterilized Milli-Q water 2-3 times. The explants (about 1.0-2.0 cm length) were allowed to partially dry up adherent water (in petri plate) and the basal region excised prior to the culture on MS medium [32] added with PGRs. Induced micro shoot bud (apical meristem of about $1-3 \mathrm{~mm}$ in height) were excised and used for callus induction (Fig. 1a, b) on solid MS medium supplemented with 2,4-D $\left(2.0 \mathrm{mg} \mathrm{L}^{-1}\right)$. After 6 weeks culture, the produced calli were cultured onto fresh medium added with the same auxin concentration (two subculture cycles). Proliferated calli were then cultured on medium added with concentrations of BAP, Kin or TDZ at 0.5, 1.0, 2.0, 3.0 or $4.0 \mathrm{mg} \mathrm{L}^{-1}$ for the de novo shoot organogenesis studies. After 6 weeks culture, the number of shoots formed/culture tube, their length, and percentage formation were evaluated, and obtained data analyzed. The micro shoots were cultivated for three subcultures on media containing same PGRs as the induction medium before separately excised for rooting on half strength MS medium added with IAA, IBA or NAA concentrations $\left(0.5-3 \mathrm{mg} \mathrm{L}^{-1}\right)$ for rhizogenesis. The micro shoots were cultivated on solid half strength MS medium added with the auxins concentrations essential for root formation, and experimental data collected after 3 weeks culture analyzed.

In this experiment, the MS medium used contained $3 \%$ sucrose and media $\mathrm{pH}$ adjusted to $5.6-5.8$ using $1 \mathrm{~N}$ $\mathrm{NaOH}$ or $\mathrm{HCl}$. The media were solidified with $8 \%$ Agar (Agar Agar Microbiology Mumbai, India) before autoclaved at $121{ }^{\circ} \mathrm{C}$ for $21 \mathrm{~min}$. All cultures were maintained under $12 \mathrm{~h}$ day/light photoperiod provided by cool fluorescent tubes (Phillips India) having photon flux density of $40 \mathrm{~W}, 50 \mu \mathrm{mol} \mathrm{m}^{-2} \mathrm{~s}^{-1}$ and culture room temperatures of $25 \pm 2{ }^{\circ} \mathrm{C}$.

\section{Histology}

For the histological studies, upper most regions of the induced micro shoots (about 1-3 mm) were fixed in formalin-acetic acid-alcohol (FAA) (95\%) that contained ethanol: glacial acetic acid: formaldehyde: water (10:1:2:7). This was followed by dehydration in graded series of ethanol $(20,30,50,70,90$, and $100 \%)$ for $20 \mathrm{~min}$ at each of the steps through three changes. The fixed tissues obtained were embedded in paraffin wax before cut into thin sections $(10 \mu \mathrm{m})$ using microtome. Sectioned strips were stained with hematoxylin and eosin followed by gentle washing with Milli-Q water and then dried at $42{ }^{\circ} \mathrm{C}$. The strips were further washed using xylol and mounted on clean glass slides using DPX followed by visual observation under a microscope (Leica, Germany).

\section{Statistical analysis}

The experiments were carried out in triplicate sets of eight replicates per treatment and the obtained data analyzed using SPSS ver. 21 (USA). Significant differences between the treatments was assessed by analysis of variance (ANOVA) followed by Tukey's range test at $\mathrm{p}<0.05$ and the obtained data presented as mean \pm standard error of the triplicate sets of experiments.

\section{Abbreviations}

MS: Murashige and Skoog medium; BAP: $N^{6}$-benzylaminopurine; TDZ: thidiazuron; Kin: kinetin; NAA: naphthalene acetic acid; IAA: indole 3-acetic acid; IBA: indole 3-butyric acid; 2,4-D: 2,4-dichlorophenoxy acetic acid.

Authors' contributions

The author read and approved the final manuscript.

\section{Acknowledgements}

Author is grateful to Department of Botany, Hamdard University New Delhi, India for providing research facilities.

\section{Competing interests}

The authors declare that they have no competing interests.

Availability of data and materials

Available on request to author.

Consent for publication

Author declares that he has consent to publish the manuscript contents.

Ethics approval and consent to participate

The research work was approved by the board of research studies, Hamdard University New Delhi, India.

Funding

Not applicable. 


\section{Publisher's Note}

Springer Nature remains neutral with regard to jurisdictional claims in published maps and institutional affiliations.

Received: 11 September 2018 Accepted: 7 January 2019

Published online: 19 January 2019

\section{References}

1. Tiwari P, Mishra BN, Sangwan NS. Phytochemical and pharmacological properties of Gymnema sylvestre: an important medicinal plant. BioMed Res Int. 2014;830285:18. https://doi.org/10.1155/2014/830285.

2. Isah T. Anticancer alkaloids from trees: development into drugs. Pharmacogn Rev. 2016;10(20):90-9. https://doi.org/10.4103/0973-7847.194047.

3. Isah T. Production of camptothecin in the elicited callus cultures of Nothapodytes nimmoniana (J. Graham) Mabberly. Chem Pap. 2017;71:1091-106. https://doi.org/10.1007/s11696-016-0056-9.

4. Isah T, Umar S, Mujib A, et al. Secondary metabolism of pharmaceuticals in the plant in vitro cultures: strategies, approaches, and limitations to achieving higher yield. Plant Cell Tissue Organ Cult. 2018;132:239-65. https://doi.org/10.1007/s11240-017-1332-2.

5. Parveen S, Chester K, Husain SA. Bioactive principles of Gymnema sylvestre R. Br. From yesterday's tradition to tomorrow's drug. Ann Phytomed. 2015:4(2):18-33.

6. Komalavalli N, Rao MV. In vitro micropropagation of Gymnema sylvestre - a multipurpose medicinal plant. Plant Cell Tissue Organ Cult. 2000;61(2):97-105. https://doi.org/10.1023/A:1006421228598.

7. Isah T. Adjustments to in vitro culture conditions and associated anomalies in plants. Acta Biol Cracov Ser Bot. 2015;57(2):9-28. https://doi. org/10.1515/abcsb-2015-0026.

8. Nataraj M, Kher MM, Teixeira da Silva JA. Micropropagation of Clerodendrum L. species: a review. Rendiconti Lincei. 2016;27(2):169-79. https:// doi.org/10.1007/s12210-015-0484-4

9. Goyal AK, Pradhan S, Basistha BC, Sen A. Micropropagation and assessment of genetic fidelity of Dendrocalamus strictus (Roxb.) nees using RAPD and ISSR markers. 3 Biotech. 2014;5:473-82. https://doi. org/10.1007/s13205-014-0244-7.

10. Cetin ES. Induction of secondary metabolite production by UV-C radiation in Vitis vinifera L. Öküzgözü callus cultures. Biol Res. 2014;47(1):37. https://doi.org/10.1186/0717-6287-47-37.

11. Al-Obaidi JR, Halabi MF, AlKhalifah NS, Asanar S, Al-Soqeer AA, Attia MF. A review on plant importance, biotechnological aspects, and cultivation challenges of jojoba plant. Biol Res. 2017;50(1):25. https://doi. org/10.1186/s40659-017-0131-x.

12. Isah T, Mujib A. In vitro plant regeneration of coffee senna (Senna occidentalis) from hypocotyl-derived callus. Acta Biol Cracov Ser Bot. 2013;55(2):120-5. https://doi.org/10.2478/abcsb-2013-0031.

13. Kher MM, Nataraj M, Teixeira da Silva JA. Micropropagation of Crataeva L. species. Rendiconti Lincei. 2016;27(2):157-67. https://doi.org/10.1007/ s12210-015-0478-2.

14. Reddy PS, Gopal GR, Sita GL. In vitro multiplication of Gymnema sylvestre R. Br._an important medicinal plant. Curr Sci. 1998;75:843-5.

15. Devi CS, Srinivasan VM. In vitro propagation of Gymnema sylvestre. Asian J Plant Sci. 2008;7:660-5.
16. Thiyagarajan $M$, Venkatachalam $P$. A reproducible and high frequency plant regeneration from mature axillary node explants of Gymnema sylvestre (Gurmur) —an important antidiabetic endangered medicinal plant. Ind Crops Prod. 2013;50:517-24. https://doi.org/10.1016/j.indcr op.2013.08.027.

17. Ashok Kumar HG, Murthy HN, Paek KY. Somatic embryogenesis and plant regeneration in Gymnema sylvestre. Plant Cell Tissue Organ Cult. 2002;71:85-8.

18. von Aderkas P, Bonga JM. Influencing micropropagation and somatic embryogenesis in mature trees by manipulation of phase change, stress and culture environment. Tree Physiol. 2000;20(14):921-8. https://doi. org/10.1093/treephys/20.14.921

19. Bonga JM. Can explant choice help resolve recalcitrance problems in in vitro propagation, a problem still acute, especially for adult conifers? Trees. 2017;31:781-9. https://doi.org/10.1007/s00468-016-1509-z.

20. Isah T. Induction of somatic embryogenesis in woody plants. Acta Physiol Plant. 2016;38:118. https://doi.org/10.1007/s11738-016-2134-6.

21. Gopi C, Vatsala TM. In vitro studies on effects of plant growth regulators on callus and suspension cultures biomass yield from Gymnema sylvestre R. Br. Afr J Biotechnol. 2006:5(12):1215-9.

22. Khatak S, Baches S, Chauhan N, Kaur A. Synergistic effects of 2, 4-D and cytokinins on callus culture establishment in rare medicinal plantGymnema sylvestre. Int J Sci Eng Res. 2014;5(2):213-8.

23. Ko CY, Al-Abdulkarim AM, Al-Jowid SM, Al-Baiz A. An effective disinfectation protocol for plant regeneration from shoot tip cultures of strawberry. Afr J Biotechnol. 2009;8(11):2611-5.

24. Rajore S, Batra A. Efficient plant regeneration via shoot tip explant in Jatropha curcas L. J Plant Biochem Biotechnol. 2005;14(1):73-5. https:// doi.org/10.1007/bf03263231.

25. Quiroz KA, Berríos M, Carrasco B, Retamales JB, Caligari PD, GarcíaGonzáles R. Meristem culture and subsequent micropropagation of Chilean strawberry (Fragaria chiloensis (L.) Duch.). Biol Res. 2017;50(1):20. https://doi.org/10.1186/s40659-017-0125-8.

26. Meng $L$, Zhang $S$, Lemaux PG. Toward molecular understanding of in vitro and in planta shoot organogenesis. Crit Rev Plant Sci. 2010;29(2):108-22. https://doi.org/10.1080/07352681003617327.

27. Isah T, Umar S. Influencing in vitro clonal propagation of Chonemorpha fragrans (moon) Alston by culture media strength, plant growth regulators, carbon source and photoperiodic incubation. J For Res. 2018;1:1.

28. Faisal M, Siddique I, Anis M. In vitro rapid regeneration of plantlets from nodal explants of Mucuna pruriens - a valuable medicinal plant. Ann Appl Biol. 2006;148:1-6.

29. Thirugnanasampandan R, Mahendran G, Bai VN. High frequency in vitro propagation of Isodon wightii (Bentham) H. Hara. Acta Physiol Plant. 2010;32:405-9.

30. Kehie M, Kumaria S, Tandon P. In vitro plantlet regeneration from nodal segments and shoot tips of Capsicum chinense Jacq. Cv. Naga King Chili. 3 Biotech. 2012;2:31-5. https://doi.org/10.1007/s13205-011-0025-5.

31. Mallaya NP, Ravishankar GA. In vitro propagation and genetic fidelity study of plant regenerated from inverted hypocotyl explants of eggplant (Solanum melongena L.) cv. Arka Shirish. 3 Biotech. 2013;3:45-52. https:// doi.org/10.1007/s13205-012-0068-2.

32. Murashige T, Skoog F. A revised medium for rapid growth and bio-assays with tobacco tissue cultures. Physiol Plant. 1962;15:473-97. https://doi. org/10.1111/j.1399-3054.1962.tb08052.x. 